\title{
BMJ Open Influence of family history on prognosis of spinal pain and the role of leisure time physical activity and body mass index: a prospective study using family- linkage data from the Norwegian HUNT study
}

\author{
Anita B Amorim, ${ }^{1}$ Paulo H Ferreira, ${ }^{1}$ Manuela L Ferreira, ${ }^{2}$ Ragnhild Lier, ${ }^{3}$ \\ Milena Simic, ${ }^{1}$ Evangelos Pappas, ${ }^{1}$ Joshua R Zadro, ${ }^{1}$ Paul Jarle Mork, ${ }^{3}$ \\ Tom IL Nilsen ${ }^{3,4}$
}

To cite: Amorim AB, Ferreira PH, Ferreira ML, et al. Influence of family history on prognosis of spinal pain and the role of leisure time physical activity and body mass index: a prospective study using family-linkage data from the Norwegian HUNT study. BMJ Open 2018;8:e022785. doi:10.1136/ bmjopen-2018-022785

- Prepublication history for this paper is available online. To view these files, please visit the journal online (http://dx.doi org/10.1136/bmjopen-2018022785).

Received 6 March 2018 Revised 28 August 2018 Accepted 31 August 2018

Check for updates

(C) Author(s) (or their employer(s)) 2018. Re-use permitted under CC BY-NC. No commercial re-use. See rights and permissions. Published by BMJ.

For numbered affiliations see end of article.

Correspondence to

Dr Tom IL Nilsen;

tom.nilsen@ntnu.no

\section{ABSTRACT}

Objectives To investigate the influence of parental chronic spinal pain on prognosis of chronic spinal pain in adult offspring, and whether offspring physical activity level and body mass index (BMI) modified this association.

Design Prospective cohort study.

Setting We used family-linked longitudinal data from the Norwegian HUNT study collected in HUNT2 (1995-1997) and HUNT3 (2006-2008).

Participants A total of 1529 offspring who reported spinal pain in HUNT2 were linked with parental data and followed up in HUNT3.

Outcomes We estimated relative risk (RR) with $95 \% \mathrm{Cl}$ for recovery from chronic spinal pain, and also from activity limiting spinal pain, in offspring related to chronic spinal pain in parents. We also investigated whether offspring leisure time physical activity and BMI modified these intergenerational associations in spinal pain.

Results A total of 540 (35\%) offspring were defined as recovered after approximately 11 years of follow-up. Offspring with both parents reporting chronic spinal pain were less likely to recover from chronic spinal pain (RR $0.83,95 \% \mathrm{Cl} 0.69$ to 0.99 ) and activity limiting spinal pain (RR $0.71,95 \% \mathrm{Cl} 0.54$ to 0.94 ), compared with offspring of parents without chronic spinal pain. Analyses stratified by $\mathrm{BMI}$ and physical activity showed no strong evidence of effect modification on these associations. However, offspring who were overweight/obese and with both parents reporting chronic spinal pain had particularly low probability of recovery from activity limiting spinal pain, compared with those who were normal weight and had parents without chronic spinal pain (RR $0.57,95 \% \mathrm{Cl} 0.39$ to 0.84 ). Conclusion Offspring with chronic spinal pain are less likely to recover if they have parents with chronic spinal pain, particularly if offspring are overweight/obese.

\section{INTRODUCTION}

Spinal pain that includes low back and neck pain is highly prevalent and a common cause
Strengths and limitations of this study

The HUNT study is a large population-based health study with longitudinal data that allows prospective analysis on the prognosis of chronic spinal pain.

- Chronic spinal pain was independently reported in parents and offspring; family relations were informed by a linkage with a national registry and the data allowed us to control for a wide range of potential confounders.

- Information on pain status, physical activity and body mass index was not updated throughout the follow-up period.

of disability worldwide. ${ }^{1}$ The natural history of spinal pain is extremely variable and may last a few days or persist for many years. ${ }^{2} \mathrm{~A}$ substantial proportion of patients recover within the first 3 months of a spinal pain episode, but around three-quarters of the remaining patients are likely to experience pain 1 year after onset. ${ }^{3}{ }^{4}$ People who fail to recover in the first few months following an acute episode are at greater risk of poor prognosis. ${ }^{5}$ Spinal pain, especially in its chronic and disabling form, could be a significant personal and financial burden, ${ }^{6}$ and may also influence families and society. ${ }^{1}$ It is therefore vital to identify factors that influence prognosis of spinal pain, which in turn can inform preventive interventions to reduce chronicity.

Family studies have suggested that chronic pain aggregate in families, ${ }^{7} 8$ with the parent-offspring transmission of chronic pain explained by genetic heritability ${ }^{9} 10$ and shared environment factors. ${ }^{11-14}$ The mean heritability of chronic low back pain is 
$67 \%,{ }^{10}{ }^{15}$ suggesting that a substantial proportion of the risk of developing chronic spinal pain is driven by genetics. However, families also share similar lifestyles and express similar health behaviours and beliefs. This suggests that shared environmental factors ${ }^{816}$ could also have an important influence on the prognosis of spinal pain. ${ }^{1718}$

Parental pain is strongly associated with the increased risk of chronic musculoskeletal pain in offspring, both during adolescence ${ }^{7}$ and in later adulthood. ${ }^{19}$ Furthermore, there is preliminary evidence that treatment response in patients with chronic low back pain is influenced by genetic factors. ${ }^{20}$ It is, therefore, possible that parental history of spinal pain influences the prognosis of spinal pain in offspring. Conversely, several studies have shown that engagement in moderate to vigorous-intensity leisure time physical activity and maintenance of a normal body mass index (BMI) are associated with better prognosis of spinal pain. ${ }^{21-25}$ Thus, a healthy offspring lifestyle could modify a possible adverse effect of parental spinal pain on prognosis of offspring spinal pain. Currently, there is limited knowledge about the influence of parental spinal pain on prognosis of spinal pain in offspring and whether this association is modified by offspring lifestyle.

In this study, we have used population-based longitudinal data from the Norwegian HUNT study to investigate the influence of parental spinal pain on the prognosis of chronic spinal pain regarding severity and activity limitation in the adult offspring. We have also investigated whether offspring leisure time physical activity and BMI modify any of these associations.

\section{METHODS}

\section{Study population}

The HUNT study is a population-based health study conducted within the county of Nord-Trøndelag, Norway. The study was performed in three consecutive waves, first in 1984-1986 (HUNT1), then in 1995-1997 (HUNT2) and last in 2006-2008 (HUNT3). In all three surveys, all residents 20 years of age and older were invited to participate, and information on lifestyle and health-related factors were collected by questionnaires and a clinical examination. Information on musculoskeletal pain was not collected at HUNT1. Therefore, those who were eligible for inclusion in this study had participated at HUNT2 and HUNT3. At HUNT2, 93898 individuals were invited to participate and $65237(65.5 \%)$ joined the study, while at HUNT3 93860 were invited and 50807 $(54.1 \%)$ agreed to participate. ${ }^{26}{ }^{27}$ Further information about selection procedures, participation and questionnaires used in the HUNT study can be found at http:/ / www.ntnu.edu/hunt.

\section{Patient involvement}

Since historical cohort data were used in this study, patients were not involved in the conduct and design of the study.

\section{Record linkage}

The unique 11-digit personal identification number held by all Norwegian citizens was used to link each participant's record to information from the Family Registry at Statistics Norway, and there by establish a link between parents and offspring who participated in one or both of HUNT2 and HUNT3. The Family Registry provides data on persons registered as legal parents, either as biological parents or through adoption. A total of 11483 offspring reported spinal pain at HUNT2, and of these, 6662 could be followed up on spinal pain status in HUNT3, approximately 11 years later. To be able to study the association between parental spinal pain and offspring prognosis of spinal pain, we selected all 1529 parent-offspring trios (ie, mother, father and adult offspring) where both the mother and the father had information on spinal pain from HUNT2.

\section{Chronic spinal pain}

At HUNT2 and HUNT3, participants were asked to complete the Standardised Nordic Questionnaire which has acceptable reliability and validity. ${ }^{28}$ The question regarding musculoskeletal pain was as follows: 'In the last year, have you had pain and/or stiffness in muscles or joints that have lasted at least 3 consecutive months?' (response options: 'no' and 'yes'). Participants who answered 'yes' were asked to indicate the affected body area(s). Offspring who reported chronic neck and/or low back pain (spinal pain) at HUNT2 were included in this study, and offspring who also reported spinal pain at HUNT3 were considered not recovered (outcome measure). Offspring reporting spinal pain at HUNT2 were also asked to indicate if the pain had led to reduced leisure time activity (response options: 'no' and 'yes') or reduced their work ability (response options: 'no', 'to some extent', 'considerably' or 'do not know'). Offspring who answered 'yes' to the question on reduced leisure time activity and/or reported work ability to be reduced 'to some extent' or 'considerably', were classified as having 'activity limiting spinal pain'. In secondary analyses, we used this information to investigate the prognosis of activity limiting spinal pain, that is, recovery was defined as not reporting activity limiting spinal pain at HUNT3. Based on the same question as described above, we obtained information on parental chronic spinal pain. Further, we created a variable with four mutually exclusive categories for presence of parental chronic spinal pain at baseline (exposure measure): 'none', 'mother', 'father' or 'both parents'.

\section{Leisure time physical activity}

Leisure time physical activity was assessed by the following question 'How much of your leisure time have you been physically active during the last year? (Think of a weekly average for the year. Your commute to work counts as leisure time)'. Participants reported the number of hours of either light (no sweating or heavy breathing) or hard (sweating and heavy breathing) activity using the response 
options 'none', 'less than 1 hour', '1-2 hours' and '3 or more hours' for each type of activity. Based on this information, we constructed a variable with four categories (combining information on light and hard activity): (1) 'inactive' (no light or hard activity), (2) 'low activity' ( $<3$ hours light and no hard activity), (3) 'moderate activity' ( $\geq 3$ hours light and/or $<1$ hour hard activity) and (4) 'high activity' (any light and $\geq 1$ hour hard activity). In the combined analyses of parental chronic spinal pain and offspring leisure time physical activity, the categories 'inactive' and 'low activity' were collapsed into one category labelled 'physically inactive' and the categories 'moderate activity' and 'high activity' were collapsed into one category labelled 'physically active'. This categorisation has been used previously in other studies based in data from HUNT. ${ }^{29}{ }^{30}$ We did not conduct analyses stratified by physical activity status on the outcome 'activity limiting spinal pain', since people with activity limiting spinal pain are likely to have limited engagement in leisure and work activities.

\section{Body mass index}

Standardised measurements of body height (to the nearest centimetre) and body weight (to the nearest half kilogram) were obtained at clinical examination. BMI was calculated as weight divided by the square of height $\left(\mathrm{kg} / \mathrm{m}^{2}\right)$, and classified into four BMI groups according to the cut-off points suggested by $\mathrm{WHO}^{31}$ : underweight (BMI $<18.5 \mathrm{~kg} / \mathrm{m}^{2}$ ), normal weight (BMI $18.5-24.9 \mathrm{~kg}$ / $\mathrm{m}^{2}$ ), overweight (BMI 25.0-29.9 $\mathrm{kg} / \mathrm{m}^{2}$ ) and obese (BMI $\left.\geq 30.0 \mathrm{~kg} / \mathrm{m}^{2}\right)$. Only 27 participants $(1 \%)$ were classified as 'underweight', and the combined analysis of parental chronic spinal pain and offspring BMI, the categories 'underweight' and 'normal weight' were collapsed into one category labelled 'normal weight'. The categories 'overweight' and 'obese' were collapsed into one category labelled 'overweight/obese'.

\section{Statistical analysis}

We used a Poisson regression model ${ }^{32-35}$ to estimate relative risk (RR) of chronic spinal pain and activity limiting spinal pain in offspring whose parents reported chronic spinal pain, using parents with no chronic spinal pain as the reference category. Precision of estimates was assessed by a $95 \%$ CI. All SEs were adjusted for within-family clustering (ie, siblings) using the vce (cluster) option in Stata, treating observations between families as independent and within families as dependent, and thus avoiding inflated precision of the estimated associations. ${ }^{36}$

Possible effect modification by offspring leisure time physical activity or offspring BMI was assessed by stratified analyses (ie, physically active vs physically inactive and normal weight vs overweight/obese) as well as by tests of the estimated relative excess risk due to interaction (RERI) (ie, departure from additive effects). We calculated RERI estimates with 95\% CIs from the following equation: $\mathrm{RERI}=\mathrm{RR}$

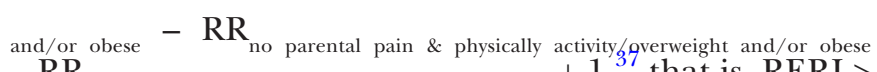
$-\mathrm{RR}$ activity/,gverweight and/or obese
+1, that is, RERI > 0 indicate a synergistic effect beyond an additive effect. Statistical interaction was also evaluated on a multiplicative scale by a likelihood ratio test of a product term in the model (these likelihood ratio tests had to be run without cluster-adjusted SEs to avoid misspecification of the model).

The main analyses (parental influence on risk of poor prognosis) were adjusted for possible confounding by offspring sex (male, female), age (continuous), BMI ('underweight', 'normal weight', 'overweight', 'obese' or 'unknown'), leisure time physical activity ('physically inactive', 'physically active' or 'unknown'), education ('<10 years', '10-12 years', '>13 years' or 'unknown') and depression ('depressed', 'not depressed' or 'unknown'). Depression was assessed using the depression subscale of the Hospital Anxiety and Depression Scale (HADS) using a score of 8 as a cut-off for a dichotomised variable. ${ }^{38-40}$

All statistical tests were two sided, and all analyses were conducted using Stata statistical software (V.13.0, STATA Corp).

\section{RESULTS}

In this prospective study of 1529 offspring with chronic spinal pain at baseline, a total of 540 (35\%) offspring were defined as recovered after approximately 11 years of follow-up. Additionally, among 775 offspring with activity limiting spinal pain, 244 were defined as recovered at follow-up. Descriptive statistics of offspring, mothers and fathers are shown in table 1 . The mean age at baseline was 32.8 (8.6) years among offspring. Most offspring were physically active $(63.9 \%)$, and nearly half of the offspring $(42.3 \%)$ were classified as overweight or obese. About one-third $(33.1 \%)$ of the offspring were current smokers, and just a small portion of offspring (20.7\%) reported having a higher education degree. A small proportion $(10.4 \%)$ of offspring had symptoms of depression according to the HADS.

\section{Chronic spinal pain and activity limiting spinal pain}

Offspring with both parents reporting chronic spinal pain were less likely to recover from chronic spinal pain (RR $0.83,95 \%$ CI 0.69 to 0.99$)$ and activity limiting spinal pain (RR $0.71,95 \%$ CI 0.54 to 0.94 ) compared with offspring with no parents with chronic spinal pain (table 2). These associations were weaker and less precise when chronic spinal pain was present in only one parent, with similar associations observed for maternal and paternal spinal pain.

\section{Physical activity}

In the stratified analysis for physical activity, there was no strong evidence of effect modification. Physically active offspring had a RR of 0.78 (95\% CI 0.62 to 0.98$)$ and physically inactive offspring a RR of 0.98 (95\% CIO.71 to 1.36$)$ 
Table 1 Baseline characteristics of the study population at HUNT2

\begin{tabular}{lccc}
\hline Variables & Offspring & Mothers & Fathers \\
\hline Participants, no & 1529 & 1529 & 1529 \\
Age, mean (SD) & $32.8(8.6)$ & $63.8(9.4)$ & $67.2(9.5)$ \\
Body mass index, mean (SD) & $25.9(5.2)$ & $28.3(7.3)$ & $27.6(6.9)$ \\
Overweight/obese, \% (n) & $42.3(799)$ & $70.6(1080)$ & $72.2(1104)$ \\
Physically active*, \% (n) & $63.9(977)$ & $43.0(510)$ & $57.7(716)$ \\
Current smoker, \% (n) & $33.1(506)$ & $26.3(400)$ & $28.5(434)$ \\
Higher educationt, \% (n) & $20.7(316)$ & $4.5(61)$ & $6.0(84)$ \\
Symptoms of depressionł, \%, (n) & $10.4(155)$ & $17.0(225)$ & $16.5(215)$ \\
\hline
\end{tabular}

*Engagement in moderate ( $\geq 3$ hours light and/or $<1$ hour hard activity per week) or high leisure time physical activity (any light and $\geq 1$ hour hard activity per week).

†College/University education.

$\ddagger$ Score $\geq 8$ on the Hospital Anxiety and Depression Scale.

(table 3). Tests of statistical interaction indicate no departure from neither multiplicative $(\mathrm{p}=0.11)$ nor additive effects (RERI $0.19 ; 95 \% \mathrm{CI}-0.17$ to 0.55 ), data not shown.

\section{Body mass index}

In the stratified analysis for BMI, there was no strong evidence of effect modification. However, offspring who were overweight or obese and with both parents reporting chronic spinal pain had the lowest probability of recovery from activity limiting spinal pain or chronic spinal pain (RR $0.57 ; 95 \% \mathrm{CI} 0.39$ to 0.84 and RR $0.79 ; 95 \% \mathrm{CI}$ 0.61 to 1.03 , respectively), compared with those who were normal weight and had parents without chronic spinal pain (table 4). In addition, there was no clear evidence of statistical interaction neither on the additive (estimates of RERI for chronic spinal pain and activity limiting spinal pain were $-0.04 ; 95 \%$ CI -0.38 to 0.30 and $-0.34 ; 95 \%$ CI -0.91 to 0.23 , respectively) nor on the multiplicative scale ( $\mathrm{p}=0.54$ and $\mathrm{p}=0.20$, respectively).

\section{DISCUSSION}

\section{Summary of findings}

The findings of this large population-based prospective family-linkage study indicate that offspring with both parents reporting chronic spinal pain are less likely to recover from chronic spinal pain and activity limiting spinal pain compared with offspring with no parent with spinal pain. Overall, there was no strong evidence that physical activity or BMI modified these associations, although the results suggest that the inverse association between parental spinal pain and recovery from activity limiting spinal pain was strongest among offspring with a high BMI. This study supports the evidence from twin studies that genetics potentially influences recovery from chronic spinal pain, ${ }^{41}$ but these intergenerational associations incorporate shared environmental factors and shared beliefs that could influence recovery. For instance, there is evidence showing that negative beliefs about pain and negative expectations about recovery predict chronic and disabling spinal pain. ${ }^{42-44}$ It seems clear that it is important to consider the family history of chronic spinal pain as well as lifestyle behaviours when identifying people at higher risk of non-recovery.

\section{Comparison of findings with previous research}

A recent systematic review showed that offspring of parents with chronic pain have poorer outcomes regarding pain, general health, psychological and family functioning as compared with offspring of parents without pain. ${ }^{45}$ The intergenerational transmission of spinal pain could be explained by genetic heritability ${ }^{9} 10$ or a family shared environment. ${ }^{1-14}$ Moreover, it has been suggested that

Table 2 Relative risk (RR) of recovery from spinal pain and activity limiting spinal pain in adult offspring associated with parental spinal pain

\begin{tabular}{|c|c|c|c|c|c|c|c|c|}
\hline \multirow[b]{2}{*}{$\begin{array}{l}\text { Parental } \\
\text { spinal pain }\end{array}$} & \multicolumn{4}{|c|}{ Offspring spinal pain } & \multicolumn{4}{|c|}{ Offspring activity limiting spinal pain } \\
\hline & $\begin{array}{l}\text { No of } \\
\text { persons }\end{array}$ & $\begin{array}{l}\text { No of } \\
\text { cases }\end{array}$ & $\begin{array}{l}\text { Crude } \\
\text { RR }\end{array}$ & $\begin{array}{l}\text { Adjusted RR* } \\
(95 \% \mathrm{Cl})\end{array}$ & $\begin{array}{l}\text { No of } \\
\text { persons }\end{array}$ & $\begin{array}{l}\text { No of } \\
\text { cases }\end{array}$ & $\begin{array}{l}\text { Crude } \\
\text { RR }\end{array}$ & $\begin{array}{l}\text { Adjusted RR* } \\
(95 \% \mathrm{Cl})\end{array}$ \\
\hline Mother & 424 & 147 & 0.88 & 0.90 (0.75 to 1.07$)$ & 214 & 62 & 0.73 & $0.74(0.56$ to 0.98$)$ \\
\hline Father & 272 & 97 & 0.90 & 0.91 (0.74 to 1.12$)$ & 127 & 40 & 0.77 & 0.78 (0.57 to 1.05$)$ \\
\hline
\end{tabular}

${ }^{*}$ Adjusted for age, sex, BMI, smoking, leisure time physical activity, education and HADS score.

BMI, body mass index; HADS, Hospital Anxiety and Depression Scale. 
Table 3 Relative risk (RR) of recovery from spinal pain in adult offspring associated with parental spinal pain; analysis stratified by leisure time physical activity

\begin{tabular}{|c|c|c|c|c|c|c|}
\hline \multirow[b]{2}{*}{ Parental spinal pain } & \multicolumn{3}{|c|}{ Physically active } & \multicolumn{3}{|c|}{ Physically inactive } \\
\hline & $\begin{array}{l}\text { No of } \\
\text { persons }\end{array}$ & No of cases & $\begin{array}{l}\text { Adjusted } \\
\text { RR* }^{\star}(95 \% \mathrm{Cl})\end{array}$ & $\begin{array}{l}\text { No of } \\
\text { persons }\end{array}$ & No of cases & $\begin{array}{l}\text { Adjusted } \\
\text { RR }^{\star}(95 \% \mathrm{Cl})\end{array}$ \\
\hline None & 229 & 97 & 1.00 (ref.) & 111 & 40 & 1.00 (ref.) \\
\hline Mother or father & 434 & 163 & $0.94(0.77$ to 1.14$)$ & 246 & 74 & 0.82 (0.60 to 1.11$)$ \\
\hline Both parents & 314 & 100 & 0.78 (0.62 to 0.98$)$ & 166 & 58 & 0.98 (0.71 to 1.35$)$ \\
\hline
\end{tabular}

${ }^{*}$ Adjusted for age, sex, BMI, smoking, education and HADS score.

BMI, body mass index; HADS, Hospital Anxiety and Depression Scale.

the genetic influence is greater in more disabling pain conditions, such as chronic widespread pain and chronic activity limiting spinal pain, rather than in acute or subacute non-debilitating pain. ${ }^{9}{ }^{10}$ It is widely accepted that lifestyle factors, such as physical activity and body weight, also play a significant role in the prognosis of chronic musculoskeletal pain. ${ }^{46}$

Some studies have suggested that people with chronic back pain who regularly engage in leisure time physical activity have better prognosis measured in terms of pain, disability and quality of life than those who are sedentary. ${ }^{29} 47$ However, there remains conflicting evidence regarding how physical activity influences the prognosis of spinal pain, ${ }^{48}$ with studies demonstrating that both low and high levels of physical activity can negatively influence the prognosis of spinal pain. ${ }^{490}$ For instance, a study found that high leisure time physical activity was related to decreased prevalence of low back pain. ${ }^{51}$ Whereas another study found that either high or low levels of leisure time physical activity was related to increased prevalence of low back pain. ${ }^{49}$ In contrast, a prospective study did not find any significant association between moderate/high levels of leisure physical activity and low back pain in young adults. ${ }^{52}$ Another follow-up study found that regular habits of leisure physical activity have no effect on recovery from low back pain. ${ }^{53}$ The inconsistency in the literature is possibly attributed to the diverse definitions and classifications of levels of physical activity. If such divergent associations with leisure time physical activity exist, this could mask a possible modifying effect of physical activity in our analyses.

The literature has provided evidence that obesity is associated with poor outcomes in people with chronic widespread pain, ${ }^{54} 55$ as well as chronic spinal pain ${ }^{29} 5657$ and also decreases the probability of recovery from chronic spinal pain regardless of the care they receive. ${ }^{25}$ However, whether BMI could modify ${ }^{30}$ the relationship between parental spinal pain on offspring recovery from chronic spinal pain has not been investigated before. Our results suggest that offspring BMI may modify on the parent-offspring association of spinal pain, with somewhat stronger associations among offspring who were classified as overweight or obese than those who were underweight or normal weight. Research has shown that interindividual differences in pain sensitivity and endogenous pain-inhibitory capacity could reflect variations in the inherent susceptibility for chronic pain, ${ }^{58}{ }^{59}$ but that a triggering exposure is required for the development

Table 4 Relative risk (RR) of recovery from spinal pain and activity limiting spinal pain in adult offspring associated with parental spinal pain; analysis stratified by BMI

\begin{tabular}{|c|c|c|c|c|c|c|}
\hline \multirow[b]{2}{*}{ Variables } & \multicolumn{3}{|c|}{ Normal weight } & \multicolumn{3}{|c|}{ Overweight/obese } \\
\hline & $\begin{array}{l}\text { No of } \\
\text { persons }\end{array}$ & No of cases & $\begin{array}{l}\text { Adjusted RR* } \\
(95 \% \mathrm{Cl})\end{array}$ & $\begin{array}{l}\text { No of } \\
\text { persons }\end{array}$ & No of cases & $\begin{array}{l}\text { Adjusted RR* } \\
(95 \% \mathrm{Cl})\end{array}$ \\
\hline \multicolumn{7}{|l|}{ Offspring spinal pain } \\
\hline \multicolumn{7}{|l|}{ Parental spinal pain } \\
\hline None & 168 & 68 & 1.00 (ref.) & 177 & 69 & 1.00 (ref.) \\
\hline Mother or father & 316 & 111 & 0.88 (0.70 to 1.12$)$ & 380 & 133 & 0.89 (0.70 to 1.12$)$ \\
\hline Both parents & 242 & 82 & $0.86(0.66$ to 1.11$)$ & 242 & 76 & 0.79 (0.61 to 1.03$)$ \\
\hline \multicolumn{7}{|c|}{ Offspring activity limiting spinal pain } \\
\hline \multicolumn{7}{|c|}{ Parental spinal pain } \\
\hline None & 86 & 34 & 1.00 (ref.) & 130 & 50 & 1.00 (ref.) \\
\hline Mother or father & 151 & 42 & 0.72 (0.49 to 1.04$)$ & 301 & 98 & 0.72 (0.51 to 0.99$)$ \\
\hline Both parents & 129 & 41 & 0.84 (0.57 to 1.24$)$ & 188 & 52 & 0.57 (0.39 to 0.84$)$ \\
\hline
\end{tabular}

${ }^{*}$ Adjusted for age, sex, leisure physical activity, smoking, education and depression.

BMI, body mass index. 
of chronic pain. ${ }^{6061}$ This could suggest that a possible genetic susceptibility for poor recovery from chronic pain $^{62} 63$ as a higher penetrance between offspring who are overweight or obese.

\section{Strengths and limitations}

This study has several strengths including the prospective design using a large population-based sample with a long follow-up period. In addition, the registry-based information on family relations allowed us to include information on chronic spinal pain obtained from parents and offspring independently and at different time points. An important aspect is that the offspring were adults at the time of data collection, indicating that the parentto-offspring association of chronic spinal pain persists into adulthood when the offspring most likely live apart from their parents. Furthermore, we were able to adjust for several offspring characteristics that could confound the parent-offspring associations of chronic spinal pain, such as age ${ }^{64} \mathrm{BMI},{ }^{57}$ leisure physical activity, ${ }^{65}$ smoking, ${ }^{64}$ depression $^{64}$ and education. ${ }^{10} 66$ However, we cannot exclude the possible residual confounding attributable to unknown or unmeasured factors.

There are some limitations that should be taken into account. First, information on chronic spinal pain was only reported at baseline and at follow-up 10-11 years later, with no information on possible changes in the status of chronic spinal pain during the follow-up period. Consequently, a person could have recovered from spinal pain at some time point between the surveys, but still report pain at follow-up. However, if parental pain reflects an underlying heritable frailty, this may have an impact also on long-term recurrence and recovery from pain. Likewise, information on leisure time physical activity and BMI was only assessed at baseline, with no information on possible changes during the follow-up period. Second, although the questions about leisure time physical activity used in this study have been reported to have good reliability and provide useful measures of leisure physical activity, ${ }^{67}$ subjective interpretations of the activity questions could have influenced the results. Besides, it is well known that self-reports may lead to under- or overestimation of the variables of interest. ${ }^{68}$ Third, a premise for inclusion into this study was that the mother, father and offspring all had to participate in the health survey. To some extent, this may have resulted in a selected and more health conscious sample than the general population. Nevertheless, it is questionable whether representativeness is a prerequisite for making valid risk assessments in epidemiological studies. ${ }^{57}$ Fourth, although the Norwegian Family Registry was used to identify family relations between parents and offspring, misclassification of biological family relations in the registry due to adoptions and non-paternity is possible. Although the influence on our results is likely to be small, such misclassification could give attenuated parent-offspring associations. Moreover, we had no information on whether the offspring shared environment with none, one or both of their biological parents during childhood. Finally, residual confounding due to unmeasured or unknown factors cannot be ruled out.

\section{CONCLUSION}

Offspring with chronic spinal pain are less likely to recover if they have parents with chronic spinal pain compared with offspring without parental chronic spinal pain. This association is stronger when the offspring present pain that interferes with their usual work and leisure activities (activity limiting spinal pain). The inverse association between parental chronic spinal pain on recovery was somewhat stronger among offspring who were overweight or obese. The association between parental chronic spinal pain and the prognosis of chronic spinal pain in the adult offspring underlines the importance of identifying those at high risk of non-recovery since they account for significant social and individual financial burden. Therefore, clinicians should consider family history of spinal pain when implementing strategies to improve recovery from chronic spinal pain. For instance, the assessment of the potential risks of physical activity and education about the range of benefits, as well as highlights the importance of maintenance of a normal body weight.

\section{Author affiliations}

${ }^{1}$ Faculty of Health Sciences, The University of Sydney, Discipline of Physiotherapy, Sydney, New South Wales, Australia

${ }^{2}$ Institute of Bone and Joint Research, The Kolling Institute, Sydney Medical School, Sydney, New South Wales, Australia

${ }^{3}$ Department of Public Health and Nursing, Norwegian University of Science and Technology, Trondheim, Norway

${ }^{4}$ Clinic of Anaesthesia and Intensive Care, St Olavs Hospital, Trondheim University Hospital, Trondheim, Norway

Acknowledgements The HUNT study is collaboration between the HUNT Research Centre (Faculty of Medicine, Norwegian University of Science and Technology (NTNU), Nord-Trøndelag County Council, Central Norway Regional Health Authority and the Norwegian Institute of Public Health. ABA holds the International Postgraduate Research Scholarship 'Science without Borders' award from the Brazilian government. PHF is funded by an NHMRC Research Fellowship and University of Sydney SOAR Fellowship. MLF holds an MRFF/NHMRC Career Development Fellowship and is a Sydney Medical Foundation Fellow.

Contributors All authors critically revised the manuscript for important intellectual content and approved the final manuscript. Please find below a detailed description of the role of each author: ABA: conception and design, analysis and interpretation of data, drafting and revision of the manuscript and final approval of the version to be published. PHF: conception and design, interpretation of data, drafting and revision of the manuscript and final approval of the version to be published. MLF: conception and design, drafting and revision of the manuscript and final approval of the version to be published. RL: conception and design, drafting and revision of the manuscript and final approval of the version to be published. MS: conception and design, drafting and revision of the manuscript and final approval of the version to be published. EP: conception and design, drafting and revision of the manuscript and final approval of the version to be published. JRZ: conception and design, interpretation of data, drafting and revision of the manuscript and final approval of the version to be published. PJM: conception and design, acquisition and interpretation of data, drafting and revision of the manuscript and final approval of the version to be published. TILN: conception and design, acquisition and interpretation of data, drafting and revision of the manuscript and final approval of the version to be published. 
Funding This research was supported by a grant from the Department of Public Health and Nursing, Norwegian University of Science and Technology, Trondheim, Norway.

Disclaimer This funding source had no role in the study's design, data collection, analysis, interpretation of the data or the decision to submit the paper for publication.

Competing interests None declared.

Patient consent Obtained.

Ethics approval The study was approved by the Regional Committee for Medical and Health Research Ethics Central Norway (ref. no. 2011/1455).

Provenance and peer review Not commissioned; externally peer reviewed.

Data sharing statement № additional data are available.

Open access This is an open access article distributed in accordance with the Creative Commons Attribution Non Commercial (CC BY-NC 4.0) license, which permits others to distribute, remix, adapt, build upon this work non-commercially, and license their derivative works on different terms, provided the original work is properly cited, appropriate credit is given, any changes made indicated, and the use is non-commercial. See: http://creativecommons.org/licenses/by-nc/4.0/.

\section{REFERENCES}

1. GBD 2015 Mortality and Causes of Death Collaborators. Global, regional, and national life expectancy, all-cause mortality, and causespecific mortality for 249 causes of death, 1980-2015: a systematic analysis for the Global Burden of Disease Study 2015. Lancet 2016;388:1459-544.

2. Vasseljen O, Woodhouse A, Bjørngaard $\mathrm{JH}$, et al. Natural course of acute neck and low back pain in the general population: the HUNT study. Pain 2013;154:1237-44.

3. Croft PR, Macfarlane GJ, Papageorgiou AC, et al. Outcome of low back pain in general practice: a prospective study. BMJ 1998;316:1356-9.

4. Itz CJ, Geurts JW, van Kleef M, et al. Clinical course of non-specific low back pain: a systematic review of prospective cohort studies set in primary care. Eur J Pain 2013;17:5-15.

5. Kent PM, Keating JL. Can we predict poor recovery from recentonset nonspecific low back pain? A systematic review. Man Ther 2008;13:12-28.

6. Gore M, Sadosky A, Stacey BR, et al. The burden of chronic low back pain: clinical comorbidities, treatment patterns, and health care costs in usual care settings. Spine 2012;37:E668-77.

7. Hoftun GB, Romundstad PR, Rygg M. Association of parental chronic pain with chronic pain in the adolescent and young adult: family linkage data from the HUNT Study. JAMA Pediatr 2013;167:61-9.

8. Saunders K, Von Korff M, Leresche L, et al. Relationship of common pain conditions in mothers and children. Clin J Pain 2007;23:204-13.

9. Kato K, Sullivan PF, Evengård B, et al. Importance of genetic influences on chronic widespread pain. Arthritis Rheum 2006;54:1682-6.

10. Hocking LJ, Morris AD, Dominiczak AF, et al. Heritability of chronic pain in 2195 extended families. Eur J Pain 2012;16:1053-63.

11. Violon A, Giurgea D. Familial models for chronic pain. Pain 1984;18:199-203.

12. Pollard CA. Family history and severity of disability associated with chronic low back pain. Psychol Rep 1985;57(3 Pt 1):813-4.

13. Payne B, Norfleet MA. Chronic pain and the family: a review. Pain 1986;26:1-22.

14. Bruehl S, France CR, France J, et al. How accurate are parental chronic pain histories provided by offspring? Pain 2005;115:390-7.

15. Ferreira PH, Beckenkamp P, Maher CG, et al. Nature or nurture in low back pain? Results of a systematic review of studies based on twin samples. Eur J Pain 2013;17:957-71.

16. Levy RL, Langer SL. Pain, disability, and symptoms among siblings of children with functional abdominal pain. J Dev Behav Pediatr 2007;28:45-6.

17. Cardol M, van den Bosch WJ, Spreeuwenberg P, et al. All in the family: headaches and abdominal pain as indicators for consultation patterns in families. Ann Fam Med 2006;4:506-11.

18. Cardol M, van Dijk $L$, van den Bosch WJ, et al. Striking variations in consultation rates with general practice reveal family influence. BMC Fam Pract 2007;8:4

19. Lier R, Nilsen TI, Mork PJ. Parental chronic pain in relation to chronic pain in their adult offspring: family-linkage within the HUNT Study, Norway. BMC Public Health 2014;14:797.
20. Luchting B, Heyn J, Hinske LC, et al. Expression of miRNA124a in CD4 Cells Reflects Response to a Multidisciplinary Treatment Program in Patients With Chronic Low Back Pain. Spine 2017;42:E226-E233.

21. Blangsted AK, Søgaard K, Hansen EA, et al. One-year randomized controlled trial with different physical-activity programs to reduce musculoskeletal symptoms in the neck and shoulders among office workers. Scand J Work Environ Health 2008;34:55-65.

22. Linton SJ, van Tulder MW. Preventive interventions for back and neck pain problems: what is the evidence? Spine 2001;26:778-87.

23. van den Heuvel SG, Heinrich J, Jans MP, et al. The effect of physical activity in leisure time on neck and upper limb symptoms. Prev Med 2005;41:260-7.

24. Krismer M, van Tulder M. Low Back Pain Group of the Bone and Joint Health Strategies for Europe Project. Strategies for prevention and management of musculoskeletal conditions. Low back pain (non-specific). Best Pract Res Clin Rheumatol 2007;21:77-91.

25. Ewald SC, Hurwitz EL, Kizhakkeveettil A. The effect of obesity on treatment outcomes for low back pain. Chiropr Man Therap 2016;24:48.

26. Krokstad S, Langhammer A, Hveem K, et al. Cohort Profile: the HUNT Study, Norway. Int J Epidemiol 2013;42:968-77.

27. Langhammer A, Krokstad S, Romundstad P, et al. The HUNT study: participation is associated with survival and depends on socioeconomic status, diseases and symptoms. BMC Med Res Methodol 2012;12:143.

28. Kuorinka I, Jonsson B, Kilbom A, et al. Standardised Nordic questionnaires for the analysis of musculoskeletal symptoms. Appl Ergon 1987;18:233-7.

29. Nilsen TI, Holtermann A, Mork PJ. Physical exercise, body mass index, and risk of chronic pain in the low back and neck/shoulders: longitudinal data from the Nord-Trondelag Health Study. Am J Epidemiol 2011;174:267-73

30. Lier R, Mork PJ, Holtermann A, et al. Familial Risk of Chronic Musculoskeletal Pain and the Importance of Physical Activity and Body Mass Index: Prospective Data from the HUNT Study, Norway. PLoS One 2016;11:e0153828.

31. World Health Organization. Physical status: the use and interpretation of anthropometry. Report of a WHO Expert Committee. Geneva: World Health Organization, 1995. (WHO Technical Report Series no. 854), W.T.R.S.n. 854).

32. Altman DG, Vergouwe $\mathrm{Y}$, Royston $\mathrm{P}$, et al. Prognosis and prognostic research: validating a prognostic model. BMJ 2009;338:b605.

33. Moons KG, Altman DG, Vergouwe Y, et al. Prognosis and prognostic research: application and impact of prognostic models in clinical practice. BMJ 2009;338:b606.

34. Moons KG, Royston P, Vergouwe $Y$, et al. Prognosis and prognostic research: what, why, and how? BMJ 2009;338:b375.

35. Royston P, Moons KG, Altman DG, et al. Prognosis and prognostic research: Developing a prognostic model. BMJ 2009;338:b604.

36. Martin RM, Smith GD, Frankel S, et al. Parents' growth in childhood and the birth weight of their offspring. Epidemiology 2004;15:308-16.

37. Andersson T, Alfredsson L, Källberg H, et al. Calculating measures of biological interaction. Eur J Epidemiol 2005;20:575-9.

38. Snaith RP. The hospital anxiety and depression scale. Health Qual Life Outcomes 2003;1:29.

39. Bjelland I, Dahl AA, Haug TT, et al. The validity of the Hospital Anxiety and Depression Scale. An updated literature review. J Psychosom Res 2002;52:69-77.

40. Zigmond AS, Snaith RP. The hospital anxiety and depression scale. Acta Psychiatr Scand 1983;67:361-70.

41. Zadro JR, Shirley D, Sánchez-Romera JF, et al. Does familial aggregation of chronic low back pain affect recovery?: A populationbased twin study. Spine 2017;42:1295-301.

42. Urquhart DM, Bell RJ, Cicuttini FM, et al. Negative beliefs about low back pain are associated with high pain intensity and high level disability in community-based women. BMC Musculoskelet Disord 2008;9:148.

43. Wertli MM, Eugster R, Held U, et al. Catastrophizing-a prognostic factor for outcome in patients with low back pain: a systematic review. Spine J 2014;14:2639-57.

44. Fujii T, Matsudaira K, Oka H. Factors associated with fear-avoidance beliefs about low back pain. J Orthop Sci 2013;18:909-15.

45. Higgins KS, Birnie KA, Chambers CT, et al. Offspring of parents with chronic pain: a systematic review and meta-analysis of pain, health, psychological, and family outcomes. Pain 2015;156:2256-66.

46. Dean E, Söderlund A. What is the role of lifestyle behaviour change associated with non-communicable disease risk in managing musculoskeletal health conditions with special reference to chronic pain? BMC Musculoskelet Disord 2015;16:87. 
47. Pinto RZ, Ferreira PH, Kongsted A, et al. Self-reported moderate-tovigorous leisure time physical activity predicts less pain and disability over 12 months in chronic and persistent low back pain. Eur J Pain 2014;18:1190-8.

48. Sitthipornvorakul E, Janwantanakul P, Purepong N, et al. The association between physical activity and neck and low back pain: a systematic review. Eur Spine J 2011;20:677-89.

49. Heneweer $\mathrm{H}$, Vanhees L, Picavet HS. Physical activity and low back pain: a U-shaped relation? Pain 2009;143:21-5.

50. Heneweer H, Staes F, Aufdemkampe G, et al. Physical activity and low back pain: a systematic review of recent literature. Eur Spine $J$ 2011;20:826-45.

51. Hartvigsen J, Christensen K. Active lifestyle protects against incident low back pain in seniors: a population-based 2-year prospective study of 1387 Danish twins aged $70-100$ years. Spine 2007;32:76-81.

52. Lunde LK, Koch M, Hanvold TN, et al. Low back pain and physical activity-A 6.5 year follow-up among young adults in their transition from school to working life. BMC Public Health 2015;15:1115.

53. Mortimer M, Pernold G, Wiktorin C. Low back pain in a general population. Natural course and influence of physical exercise-a 5-year follow-up of the Musculoskeletal Intervention Center-Norrtälje Study. Spine 2006;31:3045-51.

54. Magnusson K, Hagen KB, Natvig B. Individual and joint effects of risk factors for onset widespread pain and obesity - a population-based prospective cohort study. Eur J Pain 2016;20:1102-10.

55. Mundal I, Gråwe RW, Bjørngaard JH, et al. Prevalence and longterm predictors of persistent chronic widespread pain in the general population in an 11-year prospective study: the HUNT study. BMC Musculoskelet Disord 2014;15:213.

56. Mork PJ, Vik KL, Moe B, et al. Sleep problems, exercise and obesity and risk of chronic musculoskeletal pain: the Norwegian HUNT study. Eur J Public Health 2014;24:924-9.
57. Ray L, Lipton RB, Zimmerman ME, et al. Mechanisms of association between obesity and chronic pain in the elderly. Pain 2011;152:53-9.

58. Edwards RR. Individual differences in endogenous pain modulation as a risk factor for chronic pain. Neurology 2005;65:437-43.

59. Bradley LA. Pathophysiologic mechanisms of fibromyalgia and its related disorders. J Clin Psychiatry 2008;69(Suppl 2):6-13.

60. Buskila D, Neumann L. Genetics of fibromyalgia. Curr Pain Headache Rep 2005;9:313-5.

61. Mogil JS. Pain genetics: past, present and future. Trends Genet 2012;28:258-66.

62. Pollard TC, Batra RN, Judge A, et al. Genetic predisposition to the presence and 5-year clinical progression of hip osteoarthritis. Osteoarthritis Cartilage 2012;20:368-75.

63. Holliday KL, McBeth J. Recent advances in the understanding of genetic susceptibility to chronic pain and somatic symptoms. Curr Rheumatol Rep 2011;13:521-7.

64. Cimmino MA, Ferrone C, Cutolo M. Epidemiology of chronic musculoskeletal pain. Best Pract Res Clin Rheumatol 2011;25:173-83.

65. Holth HS, Werpen HK, Zwart JA, et al. Physical inactivity is associated with chronic musculoskeletal complaints 11 years later: results from the Nord-Trøndelag Health Study. BMC Musculoskelet Disord 2008;9:159.

66. Hagen K, Zwart JA, Svebak S, et al. Low socioeconomic status is associated with chronic musculoskeletal complaints among 46,901 adults in Norway. Scand J Public Health 2005;33:268-75.

67. Kurtze N, Rangul V, Hustvedt BE, et al. Reliability and validity of selfreported physical activity in the Nord-Trøndelag Health Study (HUNT 2). Eur J Epidemiol 2007;22:379-87.

68. Ainsworth B, Cahalin L, Buman M, et al. The current state of physical activity assessment tools. Prog Cardiovasc Dis 2015;57:387-95 